\title{
Multi-criteria decision making under the MARCOS method and the weighting methods: applied to milling, grinding and turning processes
}

\author{
Do Duc Trung* (D) \\ Faculty of Mechanical Engineering, Hanoi University of Industry, Vietnam
}

Received: 14 October 2021 / Accepted: 15 January 2022

\begin{abstract}
The efficiency of cutting machining methods is generally evaluated through many parameters such as surface roughness, material removal rate, cutting force, etc. A machining process is considered highly efficient when it meets the requirements for these parameters, such as ensuring small surface roughness, high material removal rate, or small cutting force, etc. However, for each specific machining condition, sometimes the objective functions give contradictory requirements. In this case, it is necessary to implement multi-criteria decision making, i.e., make a decision to ensure harmonization of all required objectives. In this paper, a multi-criteria decision-making study is presented for three common machining methods: milling, grinding, and turning. In each machining method, the weights of the criteria were determined by four different methods, including Equal weight, $R O C$ weight, $R S$ weight and Entropy weight. The MARCOS method was applied for multi-criteria decision making. The best alternative was found to be the same as the weights were determined using the Equal weight and Entropy weight methods. In the remaining two weighting methods, the best alternative found depends on the order where the criteria were arranged, not these methods themselves. Direction for further research has been suggested in this study as well.
\end{abstract}

Keywords: Multi-criteria decision making / MARCOS method / multi-criteria / weight

\section{Introduction}

In practice, the need to ensure multiple criteria simultaneously is always a requirement for machining processes. For example, when processing by cutting methods, it often requires small surface roughness, significant $M R R$, long tool life, small cutting force, etc. However, the above requirements are not always achieved at the same time, but sometimes they contradict each other. For example, the high-speed turning process to increase productivity often reduces tool life [1], or when grinding, the increase of the cutting depth to increase cutting productivity leads to the rise of the cutting force, the wheel wear rate as well as the spindle vibration [2]. In this case, it is necessary to carry out decision-making to ensure the harmonization of the set goals.

In practice, milling, turning, and grinding are three common machining methods. These methods account for a large volume in manufacturing mechanical products. Also, machines for the mentioned machining types are available [3]. As a result, there have been many studies with the use of different mathematical tools on multi-criteria decision making when implementing these machining methods.

\footnotetext{
* e-mail: doductrung@haui.edu.vn
}

There have been a number of multi-criteria decisionmaking methods that have been used to make multicriteria decisions for milling processes such as: using the RIM method to solve the multi-objective optimization problem of steel milling SKD11 to ensure simultaneously minimum surface roughness and cutting force, and maximum MRR [4]; the TOPSIS method is used when milling Ti-6Al-4V alloy to ensure the minimum surface roughness and maximum MRR [5]; using the PIV method to ensure the minimum surface roughness and the maximum MRR simultaneously when milling SCM440 steel [6]; the MOORA method was used to provide simultaneous surface roughness and three components of cutting force, and maximum $M R R$ when milling Ti-6Al-4V alloy [7]; the TOPSIS method and the WASPAS method were applied for getting simultaneously the minimum surface roughness and dimensional deviation, and the maximum $M R R$ when milling steel EN-31 [8]; the VIKOR method has been applied to simultaneously optimize the minimum surface texture and three cutting force components, and the maximum $M R R$ when milling aluminum alloy AA3105 [9], etc.

With the grinding method, several studies have been done in multi-criteria decision making. The works include using TOPSIS method to ensure simultaneously the 
minimum surface roughness, the minimum wheel shaft vibration, and the maximum $M R R$ when grinding DIN 1.2379 steel [2]; applying the MOORA method and COPRAS method to get both the minimum surface roughness, and the maximum $M R R$ when grinding SKD11 steel [10]; using the PSI method to ensure the minimum values of two surface texture parameters $(R a, R z)$, and the maximum $M R R$ when grinding SCM400 steel [11], etc.

Multi-criteria decision making methods have also been applied for optimization of the turning process. Some results can be listed as follows: the TOPSIS method was used to ensure the minimum surface roughness and the maximum $M R R$ simultaneously when turning EN8 steel [12]; the VIKOR method was used to ensure simultaneously the minimum surface roughness, the minimum workpiece vibration and cutting force, and the maximum $M R R$ when turning EN 10503 [13]; the VIKOR method was applied to ensure simultaneous the minimum surface roughness, the minimum cutting power, and the maximum $M R R$ when turning AISI 1040 steel [14]; the MOORA method was used to ensure the minimum cutting force, and the minimum dimensional deviation when turning Al6026T9 aluminum alloy [15]; The COPRAS method was used to ensure that the cutting power, the workpiece vibration, and the surface roughness were minimum when turning ASTM A36 steel [16]. Moreover, the PSI method was applied to simultaneously ensure the minimum surface roughness and the maximum MRR when turning EN24 [17]; the WASPAS method was used to ensure simultaneously the minimum surface roughness, the minimum cutting heat, the minimum cutting energy, and the tool wear, and the maximum $M R R$ when turning AISI D3 [18] steels, etc.

From the above analysis, it can be seen that multicriteria decision making methods (TOPSIS, VIKOR, MOORA, etc.) have been exploited a lot in multi-criteria decision making for milling, turning, grinding processes. This proves the great role of these methods in multi-criteria decision making of machining processes. Therefore, it is very necessary and useful to apply a certain new method to make multi-criteria decisions for mechanical processing processes.

$M A R C O S$ is a multi-criteria decision-making method first proposed in 2020 [19]. Although it has only been published for a short time, this method has been applied in a number of studies such as: selection of intermediate models of transport between countries in the Danube region [20]; solving multi-objective problems to reduce risks in road traffic [21]; selection of loading/unloading machines in small warehouses [22]; selection of employees for a shipping company [23]; cost calculation in construction [24]. However, up to now, there have been no studies applying the MARCOS method to multi-criteria decision making for cutting methods. This is the first reason why this study was chosen.

Most multi-criteria decision-making methods require weighting of criteria (except for a few methods such as PSI [25], CURLI [26]). However, for each different weighting method, the criteria also have different weights. In addition, the weight of the criteria greatly affects the ranking of alternatives [27]. Therefore, if only one weighting method is used to implement multi-criteria decision making, the best solution may not be the best. Therefore, to ensure that an alternative is the best, multi-criteria decision making is required when the weights of the criteria are determined by several different methods. Besides, determining the weight according to the Entropy weight method has been used in many studies, and is considered a method with high accuracy $[28,29]$. Therefore, this method along with three weight determination methods including Equal weight, $R O C$ weight, and $R S$ weight are selected to solve the multiobjective optimization problem. The application of all four methods of determining weights will increase the reliability of multi-criteria decision making. This is the second reason for conducting this study.

In fact, there is a method to determine the weight where the weight of the criteria does not depend on the ordering of the criteria. In addition, there are methods where the weight of the indicators depends heavily on the ordering of the indicators (this issue will also be clarified in the next section). This is the third reason for doing this study.

From the above analysis, in this study, the MARCOS method will be applied for multi-criteria decision making for a milling process, a grinding process, and a turning process. In each case, the weight of the criteria is also determined by four different methods. In which, the data of the milling process is carried out by the experimental process of the author of this study, while the data of the grinding process and the turning process are obtained from published studies. The main objective of this study is to determine the stability of finding the best solution using the MARCOS method for different weighting methods as well as for the order of the criteria. This is also the reason why all three methods of milling, turning and grinding have been mentioned in this study.

\section{The MARCOS method}

The steps to implement multi-criteria decision making according to the MARCOS method are as follows [19]:

Step 1: Building the initial matrix according to the following formula:

$$
X=\left[\begin{array}{ccc}
x_{11} & \cdots & x_{1 n} \\
x_{21} & \cdots & x_{2 n} \\
\vdots & \cdots & \vdots \\
x_{m 1} & \cdots & x_{m n}
\end{array}\right]
$$

where, $m$ is the number of options, $n$ is the number of criteria, $x_{m n}$ is the value of the $n$ criterion in $m$.

Step 2: Constructing an expanded initial matrix by adding an ideal alternative $(A I)$ and the anti-ideal alternative $(A A I)$.

$$
X=\begin{aligned}
& A A I \\
& A_{1} \\
& A_{2} \\
& \vdots \\
& A_{m} \\
& A I
\end{aligned}\left[\begin{array}{ccl}
x_{a a 1} & \cdots & x_{a a n} \\
x_{11} & \cdots & x_{1 n} \\
x_{21} & \cdots & x_{2 n} \\
\vdots & \vdots & \vdots \\
x_{m 1} & \cdots & x_{m n} \\
x_{a i 1} & \cdots & x_{a i n}
\end{array}\right]
$$


In which: $A A I=\min \left(x_{i j}\right) ; i=1,2, \ldots, m ; j=1,2, \ldots, n$ if $j$ is the larger the better.

$A A I=\max \left(x_{i j}\right) ; i=1,2, \ldots, m ; j=1,2, \ldots, n$ if $j$ is the smaller the better.

$A I=\max \left(x_{i j}\right) ; i=1,2, \ldots, m ; j=1,2, \ldots, n$ if $j$ is the larger the better.

$A I=\min \left(x_{i j}\right) ; i=1,2, \ldots, m ; j=1,2, \ldots, n$ if $j$ is the smaller the better.

Step 3: Normalizing the expanded initial matrix according to the formula.

$$
\begin{gathered}
n_{i j}=\frac{x_{A I}}{x_{i j}} \text { if } j \text { is the smaller the better. } \\
n_{i j}=\frac{x_{i j}}{x_{A I}} \text { if } j \text { is the lager the better. }
\end{gathered}
$$

Step 4: Building a normalized matrix taking into account the weights of the criteria, with the normalized value calculated according to the formula.

$$
v_{i j}=n_{i j} \cdot w_{j}
$$

where $w_{j}$ is the weight of the criterion $j$.

Step 5: Calculating coefficients $K_{i}^{+}$and $K_{i}^{-}$according to the formula.

$$
\begin{gathered}
K_{i}^{-}=\frac{S_{i}}{S_{A A I}} \\
K_{i}^{+}=\frac{S_{i}}{S_{A I}}
\end{gathered}
$$

In which: $S_{i}, S_{A A I}$ and $S_{A I}$ are the sum of the values of $v_{i j}, x_{a a i}$ and $x_{a i}$, respectively, where $i=1,2, \ldots, m$.

Step 6: Calculate the functions $f\left(K_{i}^{+}\right)$and $f\left(K_{i}^{-}\right)$ according to the formula.

$$
\begin{aligned}
& f\left(K_{i}^{-}\right)=\frac{K_{i}^{+}}{K_{i}^{+}+K_{i}^{i}} \\
& f\left(K_{i}^{+}\right)=\frac{K_{i}^{-}}{K_{i}^{+}+K_{i}^{i}}
\end{aligned}
$$

Step 7: Calculating the function $f(K i)$ according to the following formula and rank the alternatives.

$$
f\left(K_{i}\right)=\frac{K_{i}^{+}+K_{i}^{-}}{1+\frac{1-f\left(K_{i}^{+}\right)}{f\left(K_{i}^{+}\right)}+\frac{1-f\left(K_{i}^{-}\right)}{f\left(K_{i}^{-}\right)}}
$$

Ranking the alternatives according to the larger $f(K i)$ the better.

\section{Method of determining the weight}

\subsection{Equal weight method}

Equal weight method is used to calculate the weight according to the following formula [30].

$$
w_{j}=\frac{1}{n}
$$

In which, $n$ is the number of objectives.

\subsection{ROC weight method}

In the $R O C$ weight method, the weights of the objectives are calculated based on the following formula [31].

$$
w_{j}=\frac{1}{n} \sum_{k=1}^{n} \frac{1}{k}
$$

\subsection{RS weight method}

In the $R S$ weight method, the weight is determined by the following formula [31].

$$
w_{j}=\frac{2(n+1-i)}{n(n+1)}
$$

\subsection{Entropy weight method}

In the entropy weight method, the weights of the objectives can be found by the following steps [32].

Step 1. Determining the normalized values for objectives:

$$
p_{\mathrm{ij}}=\frac{y_{\mathrm{ij}}}{m+\sum_{i=1}^{m} y_{\mathrm{ij}}^{2}}
$$

where $y_{i j}$ is the value of criterion $j$ corresponding to test's run $i ; m$ is the number of experiments.

Step 2. Calculating the value of the Entropy measure for each criteria.

$$
\begin{aligned}
& e_{j}=-\sum_{i=1}^{m}\left[p_{\mathrm{ij}} \times \ln \left(\mathrm{p}_{\mathrm{ij}}\right)\right] \\
& -\left(1-\sum_{i=1}^{m} p_{\mathrm{ij}}\right) \times \ln \left(1-\sum_{i=1}^{m} p_{\mathrm{ij}}\right)
\end{aligned}
$$

Step 3. Calculating the weight for each criteria.

$$
w_{j}=\frac{1-e_{j}}{\sum_{j=1}^{m}\left(1-e_{j}\right)} .
$$

From the above formulas, it can be seen that, with the Equal weight method and the Entropy weight method, the weights do not depend on the order of the criteria. However, for the other two methods ( $R O C$ weight and $R S$ weight), the weight depends on the order of the criteria.

The following example will illustrate that: There are two criteria $C_{1}$, and $C_{2}$. If the criteria are arranged in the order $C_{1}, C_{2}$, then when determining the weight for them by $R O C$ weight method, the weight value of $C_{1}$ is 0.75 , the weight value of $C_{2}$ is 0.25 . If using the $R S$ weight method, the weighted value of $C_{1}$ is 0.6667 , the weighted value of $C_{2}$ is 0.3333 . However, if the criteria are ranked in the order $C_{2}, C_{1}$, then according to the $R O C$ weight method, the 
Table 1. Input parameters.

\begin{tabular}{lllll}
\hline & & & \multicolumn{2}{c}{ Value at level } \\
\cline { 3 - 5 } Cutting parameters & Unit & Symbol & 1 & 2 \\
\hline Cutting speed & $\mathrm{m} / \mathrm{min}$ & $v_{c}$ & 80 & 120 \\
Feed rate & $\mathrm{mm} / \mathrm{rev}$ & $f$ & 0.05 & 0.1 \\
Cutting width & $\mathrm{mm}$ & $a_{r}$ & 4 & 8 \\
Depth of cut & $\mathrm{mm}$ & $a_{p}$ & 0.1 & 0.15 \\
\hline
\end{tabular}

Table 2. Orthogonal matrix L9 and experimental results.

\begin{tabular}{lllllllc}
\hline & \multicolumn{4}{c}{ Cutting parameter } & & \multicolumn{2}{c}{ Response } \\
\cline { 2 - 3 } Trial. & $v_{c}(\mathrm{~m} / \mathrm{min})$ & $f(\mathrm{~mm} / \mathrm{rev})$ & $a_{r}(\mathrm{~mm})$ & $a_{p}(\mathrm{~mm})$ & & $R a(\mu \mathrm{m})$ & $M R R\left(\mathrm{~mm}^{3} / \mathrm{min}^{2}\right)$ \\
\hline$A_{1}$ & 80 & 0.05 & 4 & 0.1 & & 0.970 & 25.465 \\
$A_{2}$ & 80 & 0.10 & 8 & 0.3 & & 1.085 & 305.577 \\
$A_{3}$ & 80 & 0.15 & 12 & 0.5 & & 2.032 & 1145.916 \\
$A_{4}$ & 100 & 0.05 & 8 & 0.5 & & 0.746 & 318.310 \\
$A_{5}$ & 100 & 0.10 & 12 & 0.1 & & 0.609 & 190.986 \\
$A_{6}$ & 100 & 0.15 & 4 & 0.3 & & 1.001 & 286.479 \\
$A_{7}$ & 120 & 0.05 & 12 & 0.3 & & 0.858 & 343.775 \\
$A_{8}$ & 120 & 0.10 & 4 & 0.5 & & 0.326 & 381.972 \\
$A_{9}$ & 120 & 0.15 & 8 & 0.1 & & 1.083 & 229.183 \\
\hline
\end{tabular}

weighted value of $C_{2}$ is 0.75 , the weighted value of $C_{1}$ is 0.25 . If using the $R S$ weight method, the weighted values of $C_{2}$ are 0.6667 , and of $C_{1}$ are 0.3333 . Thus, when using the $R O C$ weight method and the $R S$ weight method, the weight of the objectives depends on the ordering of the criteria. Does this issue affect the ranking of alternatives? This content will be clarified in the next part of the article.

\section{Multi-criteria decision making for milling}

\subsection{Milling experiment}

It is very important to build the setup and conduct the experiment, as well as analyze its results. These things need to be done carefully because they will affect the accuracy of the experiment. However, the main purpose of this study is to determine the stability of the MARCOS method for different weighting methods. The experimental setup can be described as follows: SKS3 steel was used during the test. This is a widely used steel for making dies, cutters, etc. due to its high hardness, high wear resistance. Steel samples are available in length, width and height of $120 \mathrm{~mm}, 40 \mathrm{~mm}$ and $40 \mathrm{~mm}$ respectively. The cutting tool used in this study is a TiN coated cutter. This is a cutting tool with high hardness, wear resistance, high toughness, and low chipping rate during machining $[33,34]$. The cutter body has a diameter of $20 \mathrm{~mm}$, on which two symmetrical cutting pieces are mounted. The experiment was designed according to the Taguchi method with four input parameters that are variable variables in each experiment.
Each input parameter was selected with three levels of values as shown in Table 1 [34,35]. The experiments were performed on a 3-axis CNC milling machine TXC540 (Taiwan).

The experimental matrix is shown in Table 2. The experiments were performed according to the experimental plan in this table. The $M R R$ is calculated according to formula (17), where $d$ is the tool diameter, $v_{c}$ is the cutting speed, $f$ is the feed rate, $a_{r}$ is the cutting width, $a_{p}$ is the depth of cut. The surface roughness was measured with an SJ-201. The response values of the experiments have also been included in Table 2 .

$$
M R R=\frac{1}{\pi \cdot d} \cdot 1000 \cdot v_{c} \cdot f \cdot a_{r} \cdot a_{p}
$$

The purpose of the study is to determine the experiment to ensure the minimum $R a$ and maximum $M R R$ simultaneously. However, the experimental results (Tab. 2) show that $R a$ has the smallest value in experimental run $\# 8$, but $M R R$ has the largest value in run $\# 3$. Therefore, it is necessary to perform multi-criteria decision making to determine the experimental run where $R a$ is considered to be "smallest" and $M R R$ is considered "maximum".

\subsection{Determining the weights for the criteria}

Formula (11) is used to determine the weights for the criteria according to the Equal weight method. The weight of each criterion is determined by 0.5 . 
Table 3. Expanded initial matrix.

\begin{tabular}{llr}
\hline & $R_{a}$ & \multicolumn{1}{c}{$M R R$} \\
\hline$A A I$ & 2.032 & 25.465 \\
$A_{1}$ & 0.970 & 25.465 \\
$A_{2}$ & 1.085 & 305.577 \\
$A_{3}$ & 2.032 & 1145.916 \\
$A_{4}$ & 0.746 & 318.310 \\
$A_{5}$ & 0.609 & 190.986 \\
$A_{6}$ & 1.001 & 286.479 \\
$A_{7}$ & 0.858 & 343.775 \\
$A_{8}$ & 0.326 & 381.972 \\
$A_{9}$ & 1.083 & 229.183 \\
$A I$ & 0.326 & 1145.916 \\
\hline
\end{tabular}

Table 4. Normalized matrix.

\begin{tabular}{lll}
\hline & $R_{a}$ & $M R R$ \\
\hline$A A I$ & 0.1604 & 0.0222 \\
$A_{1}$ & 0.3361 & 0.0222 \\
$A_{2}$ & 0.3005 & 0.2667 \\
$A_{3}$ & 0.1604 & 1.0000 \\
$A_{4}$ & 0.4370 & 0.2778 \\
$A_{5}$ & 0.5353 & 0.1667 \\
$A_{6}$ & 0.3257 & 0.2500 \\
$A_{7}$ & 0.3800 & 0.3000 \\
$A_{8}$ & 1.0000 & 0.3333 \\
$A_{9}$ & 0.3010 & 0.2000 \\
$A I$ & 1.0000 & 1.0000 \\
\hline
\end{tabular}

Formula (12) is used to determine the weight of the criteria according to the $R O C$ weight method. The weights of the criteria $R a, M R R$ were found to be 0.75 and 0.25 , respectively.

Formula (13) is used to determine the weight of the criteria according to the $R S$ weight method. The weights of the criteria $R a, M R R$ were found to be 0.6667 and 0.3333 , respectively.

The weights for the criteria $R a$ and $M R R$ according to the Entropy method are calculated according to the formulas (14) to (17) and the results are 0.6618 and 0.3382 , respectively.

\subsection{Applying the MARCOS method for multi-criteria decision making}

Formula (1) is used to determine the original matrix. This matrix is the last two columns in Table 2.

Formula (2) is used to build the expanded initial matrix. The results are presented in Table 3 .

Formulas (3), (4) are used to determine the normalized matrix. The results are presented in Table 4.
Table 5. Normalized matrix with weights.

\begin{tabular}{lll}
\hline & $R_{a}$ & $M R R$ \\
\hline$A A I$ & 0.0802 & 0.0111 \\
$A_{1}$ & 0.1680 & 0.0111 \\
$A_{2}$ & 0.1502 & 0.1333 \\
$A_{3}$ & 0.0802 & 0.5000 \\
$A_{4}$ & 0.2185 & 0.1389 \\
$A_{5}$ & 0.2677 & 0.0833 \\
$A_{6}$ & 0.1628 & 0.1250 \\
$A_{7}$ & 0.1900 & 0.1500 \\
$A_{8}$ & 0.5000 & 0.1667 \\
$A_{9}$ & 0.1505 & 0.1000 \\
$A I$ & 0.5000 & 0.5000 \\
\hline
\end{tabular}

Formula (5) is used to build a normalized matrix taking into account the weights of the criteria. In which, the weight of the criteria is determined by the equal weight method (i.e. $w_{j}=0.5$, with $j=1 \div 2$ ). The results are presented in Table 5.

Apply formulas (6), (7), (8), (9) and (10) to calculate the respective values $K_{i}^{-}, K_{i}^{+}, f\left(K_{i}^{-}\right), f\left(K_{i}^{+}\right)$and $f\left(K_{i}\right)$. The results are presented in Table 6 . The results of ranking the alternatives according to the value of $f\left(K_{i}\right)$ have also been included in this table.

Proceeding in the same way, the alternatives corresponding to different weighting methods ( $R O C$ weight, $R S$ weight, Entropy weight) are ranked as shown in Table 7 .

The results in Table 7 show that, with different weighting methods, the ranking results of the alternatives are also different. This is in complete agreement with the comment in [27]. However, it is surprising to find that with all four different weighting methods, $A_{8}$ is still determined to be the best solution, and $A_{1}$ is still considered the worst solution. The data in Table 2 demonstrates that the $M R R$ at $A_{1}$ is significantly lower than that at other alternatives. Hence, it is appropriate to conclude that $A_{1}$ is the worst alternative. In contrast, $R a$ at $A_{8}$ is the lowest among the eight alternatives, while the $M R R$ at $A_{8}$ is only lower than the $M R R$ at $A_{3}$. For that reason, $A_{8}$ is considered as the best. This is explained by the fact that the MARCOS method considers the ideal solution $(A I)$ and the anti-ideal solution $(A A I)$. In addition, when the weight of the criteria is determined by the $R S$ method and the Entropy method, the ranking order of the alternatives is completely identical.

\section{Multi-criteria decision making for grinding process}

In this section, the results of the steel grinding test SCM400 [11] were used. In this experiment, nine experiments with the Taguchi design were conducted. At each experiment, the part speed, feed rate, and depth of cut were changed. In addition, surface roughness $(R a, R z)$ was measured and $M R R$ was calculated with each experiment. The results of this experiment are presented in Table 8. In this study, the 
Table 6. Some parameters in MARCOS and ranking of alternatives.

\begin{tabular}{lllllll}
\hline Trial. & $K_{i}^{-}$ & $K_{i}^{+}$ & $f\left(K_{i}^{-}\right)$ & $f\left(K_{i}^{+}\right)$ & $f\left(K_{i}\right)$ & Rank \\
\hline$A_{1}$ & 0.006515 & 0.000156 & 0.023427 & 0.976573 & 0.000156 & 9 \\
$A_{2}$ & 0.010313 & 0.000247 & 0.023427 & 0.976573 & 0.000247 & 7 \\
$A_{3}$ & 0.021101 & 0.000506 & 0.023427 & 0.976573 & 0.000506 & 2 \\
$A_{4}$ & 0.012997 & 0.000312 & 0.023427 & 0.976573 & 0.000312 & 3 \\
$A_{5}$ & 0.012764 & 0.000306 & 0.023427 & 0.976573 & 0.000306 & 4 \\
$A_{6}$ & 0.010468 & 0.000251 & 0.023427 & 0.976573 & 0.000251 & 6 \\
$A_{7}$ & 0.012364 & 0.000297 & 0.023427 & 0.976573 & 0.000296 & 5 \\
$A_{8}$ & 0.024245 & 0.000582 & 0.023427 & 0.976573 & 0.000581 & 1 \\
$A_{9}$ & 0.009110 & 0.000219 & 0.023427 & 0.976573 & 0.000218 & 8 \\
\hline
\end{tabular}

Table 7. Ranking of alternatives for different weighting methods

\begin{tabular}{|c|c|c|c|c|c|c|}
\hline \multirow[b]{2}{*}{ Trial. } & \multicolumn{2}{|c|}{ Criteria } & \multicolumn{4}{|c|}{ Weighting methods } \\
\hline & $R a(\mu \mathrm{m})$ & $M R R\left(\mathrm{~mm}^{3} / \mathrm{min}\right)$ & Equal weight & $R O C$ weight & $R S$ weight & Entropy weight \\
\hline$A_{1}$ & 0.970 & 25.465 & 9 & 9 & 9 & 9 \\
\hline$A_{2}$ & 1.085 & 305.577 & 7 & 7 & 7 & 7 \\
\hline$A_{3}$ & 2.032 & 1145.916 & 2 & 4 & 2 & 2 \\
\hline$A_{4}$ & 0.746 & 318.310 & 3 & 3 & 4 & 4 \\
\hline$A_{5}$ & 0.609 & 190.986 & 4 & 2 & 3 & 3 \\
\hline$A_{6}$ & 1.001 & 286.479 & 6 & 6 & 6 & 6 \\
\hline$A_{7}$ & 0.858 & 343.775 & 5 & 5 & 5 & 5 \\
\hline$A_{8}$ & 0.326 & 381.972 & 1 & 1 & 1 & 1 \\
\hline$A_{9}$ & 1.083 & 229.183 & 8 & 8 & 8 & 8 \\
\hline
\end{tabular}

PSI method for multi-criteria decision making was used. The purpose of this study is to identify one experiment out of a total of nine experiments where $R a$ and $R z$ are the smallest and the $M R R$ is the largest. However, in this study, the author did not compare the MARCOS method and the PSI method, but determined the stability of the multi-criteria decision making by the MARCOS method when using the identification methods assign different weights.

The weights of the criterias have been determined according to four methods including the Equal weight, the $R O C$ weight, the $R S$ weight, and the Entropy weight and the results are presented in Table 9 .

With four sets of weights of the criteria as shown in Table 9, the MARCOS method is applied to rank the alternatives. The results obtained are presented in Table 10.

The ranking results of the alternatives in Table 10 show that, with different weighting methods, the ranking results of the options are also different [27]. However, with all four different weighting methods, $A_{4}$ was determined to be the best solution. In addition, when using the Equal weight method, the $R O C$ weight method, and $R S$ weight method, $A_{2}$ is the worst option. According to the data in Table 8, both $R a$ and $R z$ at $A_{4}$ are the lowest among nine experiments. As a result, $A_{4}$ is found as the best solution.
On the contrary, $R z$ is the highest and $R a$ is also great (only lower than $R a$ at $A_{6}$ ) at $A 2$. Therefore, it is appropriate to conclude that $A_{2}$ is the worst option.

\section{Multi-criteria decision making for turning process}

In this section, 6063 aluminum turning test results [36] were used. In which, twenty-seven experiments were designed according to the Taguchi method with input parameters as part speed, feed amount, depth of cut, and percentage of $\mathrm{TiC}$ additive in lubricant. At each experiment, surface roughness $(R z)$, cutting force $(F c)$, and $M R R$ were calculated. The obtained results are shown in Table 11. In this study, the WASPAS method and the $M O O R A$ method were also used for multi-criteria decision making to determine the experiment that simultaneously ensures the largest $M R R, F c$ and $R z$ are the smallest. However, the comparison of the MARCOS methods, the WASPAS method, and the MOORA method was not performed, but only the stability assessment of multicriteria decision-making was carried out by the $M A R C O S$ method corresponding to the identified methods different weights. 
Table 8. Experimental results of SCM400 steel grinding process [11].

\begin{tabular}{lllllll}
\hline \multirow{2}{*}{ Trial. } & \multicolumn{3}{c}{ Cutting parameter } & \multicolumn{3}{c}{ Response } \\
\cline { 2 - 7 }$A_{1}$ & 400 & $f(\mathrm{~mm} / \mathrm{rev})$ & $a_{r}(\mathrm{~mm})$ & $R a(\mu \mathrm{m})$ & $R z(\mu \mathrm{m})$ & $M R R\left(\mathrm{~mm}^{3} / \mathrm{min}^{2}\right)$ \\
$A_{2}$ & 400 & 0.05 & 0.01 & 0.51 & 2.06 & 82.439 \\
$A_{3}$ & 400 & 0.075 & 0.015 & 0.73 & 4.52 & 105.976 \\
$A_{4}$ & 600 & 0.09 & 0.02 & 0.59 & 4.24 & 169.533 \\
$A_{5}$ & 600 & 0.05 & 0.015 & 0.38 & 1.77 & 70.650 \\
$A_{6}$ & 600 & 0.075 & 0.02 & 0.42 & 3.53 & 141.277 \\
$A_{7}$ & 800 & 0.09 & 0.01 & 0.76 & 2.12 & 84.795 \\
$A_{8}$ & 800 & 0.05 & 0.02 & 0.39 & 2.35 & 94.185 \\
$A_{9}$ & 800 & 0.075 & 0.01 & 0.59 & 1.97 & 70.662 \\
\hline
\end{tabular}

Table 9. Weights of objectives corresponding to different weighting methods.

\begin{tabular}{llll}
\hline & \multicolumn{3}{c}{ Criteria } \\
\cline { 2 - 4 } Weighting methods & $R a$ & $R z$ & $M R R$ \\
\hline Equal weight & $1 / 3$ & $1 / 3$ & $1 / 3$ \\
$R O C$ weight & 0.6111 & 0.2778 & 0.1111 \\
$R S$ weight & 0.5000 & 0.3333 & 0.1667 \\
Entropy weight & 0.4138 & 0.3641 & 0.2222 \\
\hline
\end{tabular}

Table 10. Ranking of alternatives for different weighting methods.

\begin{tabular}{|c|c|c|c|c|c|c|c|}
\hline \multirow[b]{2}{*}{ Trial. } & \multicolumn{3}{|c|}{ Criterias } & \multicolumn{4}{|c|}{ Weighting methods } \\
\hline & $\underline{R a(\mu \mathrm{m})}$ & $R z(\mu \mathrm{m})$ & $M R R\left(\mathrm{~mm}^{3} / \mathrm{min}\right)$ & Equal weight & $R O C$ weight & $R S$ weight & Entropy weight \\
\hline$A_{1}$ & 0.51 & 2.06 & 82.439 & 4 & 4 & 4 & 5 \\
\hline$A_{2}$ & 0.73 & 4.52 & 105.976 & 9 & 9 & 9 & 3 \\
\hline$A_{3}$ & 0.59 & 4.24 & 169.533 & 5 & 6 & 6 & 7 \\
\hline$A_{4}$ & 0.38 & 1.77 & 70.650 & 1 & 1 & 1 & 1 \\
\hline$A_{5}$ & 0.42 & 3.53 & 141.277 & 3 & 3 & 3 & 4 \\
\hline$A_{6}$ & 0.76 & 2.12 & 84.795 & 8 & 8 & 7 & 8 \\
\hline$A_{7}$ & 0.39 & 2.35 & 94.185 & 2 & 2 & 2 & 2 \\
\hline$A_{8}$ & 0.59 & 1.97 & 70.662 & 6 & 5 & 5 & 6 \\
\hline$A_{9}$ & 0.64 & 3.18 & 127.171 & 7 & 7 & 8 & 9 \\
\hline
\end{tabular}

Four methods Equal weight, $R O C$ weight, $R S$ weight and Entropy weight were again used to determine the weights for the criteria, and the results are presented in Table 12. The MARCOS method was also applied to rank the indicators. The plans and results are presented in Table 13.

The ranking results of the alternatives in Table 13 also show that, with different weighting methods, the ranking results of the alternatives are also different [27]. However, alternative $A_{16}$ was determined to be the best option, and alternative $A_{21}$ was still determined to be the worst option. From the data in Table 11, the $M R R$ is remarkably high (only lower than the $M R R$ at $A_{18}$ ) and the $F c$ and $R z$ at $A_{16}$ by are fairly low at $A_{16}$. This contributes to the conclusion that $A_{16}$ is the best alternative.
From the ranking results of the three machining processes (milling, grinding, turning) (Tables 7, 10 and 13), as well as from the content discussed about them, the MARCOS method always determines the best test for although the weights of the criteria are determined by different methods. Furthermore, although the number of experiments is different in the milling, grinding and turning cases, the best alternative in each case is defined to be the same using the different weighting methods. This is explained by the fact that the MARCOS method refers to the ideal and anti-ideal alternatives [19].

However, if the weights of the indicators are determined by the Equal weight method or the Entropy weight method, their values do not depend on the order of the 
Table 11. Experimental results of 6063 aluminum turning process [36].

\begin{tabular}{|c|c|c|c|c|c|c|c|}
\hline \multirow[b]{2}{*}{ Trial. } & \multicolumn{4}{|c|}{ Input parameters } & \multicolumn{3}{|c|}{ Responses } \\
\hline & $n(\mathrm{rev} / \mathrm{min})$ & $f(\mathrm{~mm} / \mathrm{rev})$ & $a_{r}(\mathrm{~mm})$ & $\mathrm{TiC}(\%)$ & $M R R\left(\mathrm{~mm}^{3} / \mathrm{min}\right)$ & $F_{c}(\mathrm{~N})$ & $R z(\mu \mathrm{m})$ \\
\hline$A_{1}$ & 950 & 0.1 & 0.3 & 10 & 5892 & 128 & 4.91 \\
\hline$A_{2}$ & 950 & 0.13 & 0.3 & 5 & 6128 & 118 & 4.11 \\
\hline$A_{3}$ & 700 & 0.13 & 0.1 & 10 & 6523 & 120 & 4.55 \\
\hline$A_{4}$ & 950 & 0.14 & 0.2 & 10 & 6395 & 123 & 4.56 \\
\hline$A_{5}$ & 950 & 0.13 & 0.1 & 15 & 6129 & 120 & 4.4 \\
\hline$A_{6}$ & 950 & 0.13 & 0.3 & 15 & 5569 & 123 & 4.32 \\
\hline$A_{7}$ & 1200 & 0.16 & 0.2 & 10 & 5235 & 116 & 3.88 \\
\hline$A_{8}$ & 1200 & 0.13 & 0.1 & 10 & 5702 & 120 & 4.4 \\
\hline$A_{9}$ & 950 & 0.16 & 0.1 & 10 & 5269 & 119 & 4.46 \\
\hline$A_{10}$ & 950 & 0.1 & 0.1 & 10 & 4892 & 111 & 3.98 \\
\hline$A_{11}$ & 700 & 0.1 & 0.2 & 10 & 6524 & 110 & 4.01 \\
\hline$A_{12}$ & 950 & 0.16 & 0.2 & 15 & 5689 & 113 & 4.26 \\
\hline$A_{13}$ & 700 & 0.13 & 0.2 & 15 & 5512 & 126 & 4.74 \\
\hline$A_{14}$ & 700 & 0.16 & 0.2 & 10 & 6582 & 124 & 5.13 \\
\hline$A_{15}$ & 950 & 0.13 & 0.2 & 10 & 5834 & 116 & 4.28 \\
\hline$A_{16}$ & 1200 & 0.13 & 0.2 & 5 & 6924 & 118 & 4.42 \\
\hline$A_{17}$ & 950 & 0.16 & 0.1 & 10 & 6596 & 115 & 4.16 \\
\hline$A_{18}$ & 950 & 0.13 & 0.2 & 10 & 6952 & 121 & 4.53 \\
\hline$A_{19}$ & 1200 & 0.1 & 0.2 & 10 & 6524 & 126 & 4.69 \\
\hline$A_{20}$ & 700 & 0.13 & 0.3 & 10 & 5362 & 124 & 4.52 \\
\hline$A_{21}$ & 1200 & 0.13 & 0.3 & 10 & 4206 & 120 & 4.12 \\
\hline$A_{22}$ & 700 & 0.13 & 0.2 & 5 & 4857 & 119 & 3.73 \\
\hline$A_{23}$ & 950 & 0.13 & 0.1 & 5 & 5695 & 120 & 4.4 \\
\hline$A_{24}$ & 950 & 0.16 & 0.2 & 5 & 5425 & 124 & 4.54 \\
\hline$A_{25}$ & 950 & 0.1 & 0.2 & 10 & 6325 & 125 & 4.71 \\
\hline$A_{26}$ & 1200 & 0.13 & 0.2 & 10 & 6321 & 116 & 4.44 \\
\hline$A_{27}$ & 950 & 0.1 & 0.2 & 5 & 5125 & 117 & 4.06 \\
\hline
\end{tabular}

Table 12. Weights of criteria corresponding to different weighting methods.

\begin{tabular}{llll}
\hline & \multicolumn{2}{c}{ Criteria } & $R z$ \\
\cline { 2 - 4 } Weight method & $M R R$ & $F c$ & $1 / 3$ \\
\hline Equal weight & $1 / 3$ & $1 / 3$ & 0.1111 \\
$R O C$ weight & 0.6111 & 0.2778 & 0.1667 \\
$R S$ weight & 0.5000 & 0.3333 & 0.2508 \\
Entropy weight & 0.6766 & 0.0727 & \\
\hline
\end{tabular}

criteria. However, with two methods $R O C$ weight and $R S$ weight, the result is different. The question is when the criteria are arranged in different order, will it make the ranking of the different criteria or not. Tables $14-16$ present the ranking results of the plans for milling, grinding, and turning when the order of criteria is arranged in different ways.
Table 14 shows:

- When the order of criteria is arranged in the order $R a$ to $M R R$, then $A_{8}$ is considered the best option in both cases where the weight is determined by $R O C$ weight method and $R S$ weight method. According to experimental data in Table $2, A_{8}$ is the solution with the smallest $R a$ $(R a=0.326 \mu \mathrm{m})$. 
Table 13. Ranking of alternatives for different weighting methods.

\begin{tabular}{|c|c|c|c|c|c|c|c|}
\hline \multirow{2}{*}{ Trial. } & \multicolumn{3}{|c|}{ Criteria } & \multicolumn{4}{|c|}{ Weighting methods } \\
\hline & $M R R(\mathrm{~mm} 3 / \mathrm{min})$ & $F c(\mathrm{~N})$ & $R z(\mu \mathrm{m})$ & Equal weight & $R O C$ weight & $R S$ weight & Entropy method \\
\hline$A_{1}$ & 5892 & 128 & 4.91 & 25 & 17 & 20 & 17 \\
\hline$A_{2}$ & 6128 & 118 & 4.11 & 5 & 10 & 7 & 9 \\
\hline$A_{3}$ & 6523 & 120 & 4.55 & 7 & 5 & 5 & 5 \\
\hline$A_{4}$ & 6395 & 123 & 4.56 & 12 & 9 & 8 & 8 \\
\hline$A_{5}$ & 6129 & 120 & 4.4 & 11 & 12 & 11 & 12 \\
\hline$A_{6}$ & 5569 & 123 & 4.32 & 21 & 18 & 18 & 18 \\
\hline$A_{7}$ & 5235 & 116 & 3.88 & 9 & 19 & 17 & 19 \\
\hline$A_{8}$ & 5702 & 120 & 4.4 & 17 & 15 & 15 & 15 \\
\hline$A_{9}$ & 5269 & 119 & 4.46 & 22 & 23 & 22 & 25 \\
\hline$A_{10}$ & 4892 & 111 & 3.98 & 13 & 24 & 19 & 26 \\
\hline$A_{11}$ & 6524 & 110 & 4.01 & 3 & 3 & 3 & 3 \\
\hline$A_{12}$ & 5689 & 113 & 4.26 & 8 & 14 & 14 & 14 \\
\hline$A_{13}$ & 5512 & 126 & 4.74 & 26 & 21 & 26 & 22 \\
\hline$A_{14}$ & 6582 & 124 & 5.13 & 20 & 7 & 10 & 10 \\
\hline$A_{15}$ & 5834 & 116 & 4.28 & 10 & 13 & 12 & 13 \\
\hline$A_{16}$ & 6924 & 118 & 4.42 & 1 & 1 & 1 & 1 \\
\hline$A_{17}$ & 6596 & 115 & 4.16 & 2 & 4 & 2 & 4 \\
\hline$A_{18}$ & 6952 & 121 & 4.53 & 4 & 2 & 4 & 2 \\
\hline$A_{19}$ & 6524 & 126 & 4.69 & 15 & 8 & 9 & 6 \\
\hline$A_{20}$ & 5362 & 124 & 4.52 & 24 & 25 & 25 & 23 \\
\hline$A_{21}$ & 4206 & 120 & 4.12 & 27 & 27 & 27 & 27 \\
\hline$A_{22}$ & 4857 & 119 & 3.73 & 14 & 26 & 23 & 24 \\
\hline$A_{23}$ & 5695 & 120 & 4.4 & 18 & 16 & 16 & 16 \\
\hline$A_{24}$ & 5425 & 124 & 4.54 & 23 & 20 & 24 & 20 \\
\hline$A_{25}$ & 6325 & 125 & 4.71 & 19 & 11 & 13 & 11 \\
\hline$A_{26}$ & 6321 & 116 & 4.44 & 6 & 6 & 6 & 7 \\
\hline$A_{27}$ & 5125 & 117 & 4.06 & 16 & 22 & 21 & 21 \\
\hline
\end{tabular}

Table 14. Ranking of alternatives of milling according to the arrangement of criteria.

\begin{tabular}{lllll}
\hline & \multicolumn{2}{c}{$R O C$ weight } & \multicolumn{2}{c}{$R S$ weight } \\
\cline { 2 - 5 } Trial. & $\begin{array}{l}\text { Ra, MRR } \\
(1)\end{array}$ & $\begin{array}{l}M R R, R a \\
(2)\end{array}$ & $\begin{array}{l}\text { Ra, MRR } \\
(3)\end{array}$ & $\begin{array}{c}M R R, R a \\
(4)\end{array}$ \\
\hline$A_{1}$ & 9 & 9 & 9 & 9 \\
$A_{2}$ & 7 & 5 & 7 & 6 \\
$A_{3}$ & 4 & 1 & 2 & 1 \\
$A_{4}$ & 3 & 4 & 4 & 3 \\
$A_{5}$ & 2 & 7 & 3 & 5 \\
$A_{6}$ & 6 & 6 & 6 & 7 \\
$A_{7}$ & 5 & 3 & 5 & 4 \\
$A_{8}$ & 1 & 2 & 1 & 2 \\
$A_{9}$ & 8 & 8 & 8 & 8 \\
\hline
\end{tabular}




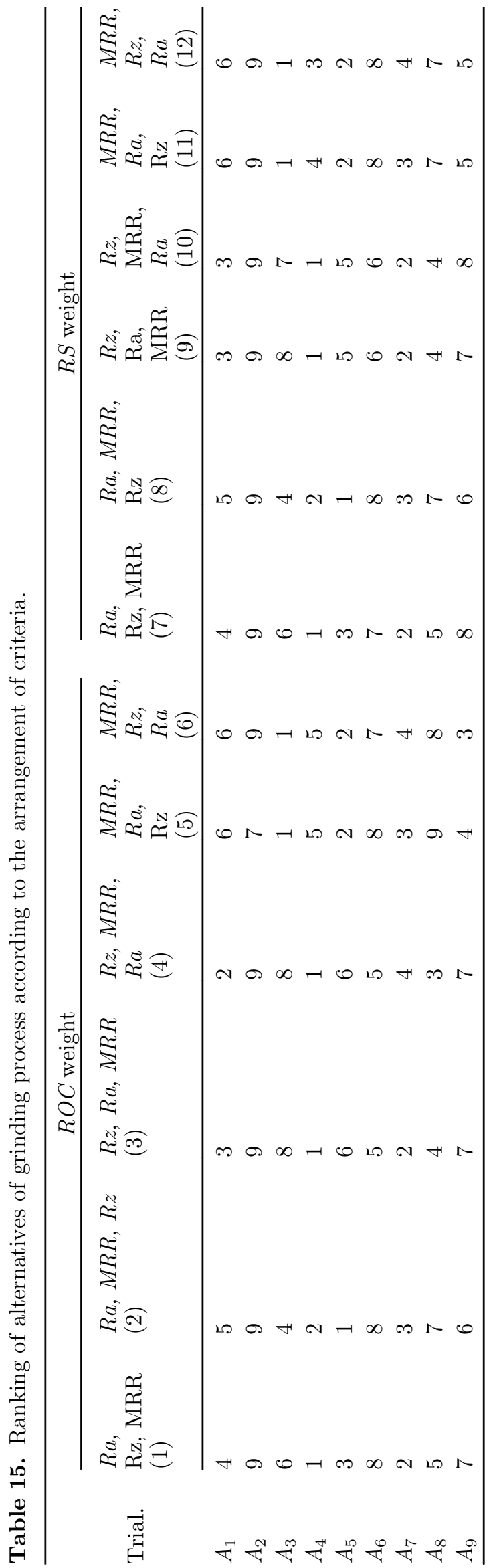

- When the order of criteria is arranged in the order $M R R$ to $R a, A_{3}$ is determined to be the best option. At $A_{3}$. In Table 2, the $M R R$ also has the largest value $(M R R=$ $\left.1145,916 \mathrm{~mm}^{3} / \mathrm{min}\right)$.

This is considered as the result of ranking the options that have oriented towards the priority for the criterion ranked in the top position. Specifically, when the criteria are arranged in the order $R a$ to $M R R$, the best solution is also the one with the smallest $R a$. Besides, when the criteria are arranged in order of $M R R$ to $R a$, the best solution is also the one with the largest $M R R$. It is easy to see that the best solution depends on the ordering of the criteria, not on the weighting method.

From the Table 15, it was reported that:

- When the criteria are arranged in the order $R a, R z$ to $M R R$ (column (1) and column (7)), then $A_{4}$ is determined to be the best option. From Table 8 , in run $A_{4}$, both $R a$ and $R z$ have the smallest value $(R a=0.38 \mu \mathrm{m}$, $R z=1.77 \mu \mathrm{m})$.

- When the criteria are arranged in the order $R a, M R R$ to $R z$ (column (2) and column (8)), $A_{5}$ is determined to be the best solution with which $R a$ is very small $(R a=0.42 \mu \mathrm{m})$, and $M R R$ is the largest $\left(M R R=141.277 \mathrm{~mm}^{3} / \mathrm{min}\right)$.

- In columns (3), (4), (9) and (10) are the results of ranking methods when $R z$ is selected as the first criterion. In all four cases, $A_{4}$ is determined to be the best solution, and in this case, $R z$ also has the smallest value.

- When MRR is selected as the first criterion (columns (5), (6), (11), (12)), then $A_{3}$ is determined as the best option. At $A_{3}, M R R$ also has the largest value.

Thus, from Table 15, it can be seen that the best solution is towards the one in which the first ranking criterion achieves the best results. Specifically, if $R a$ is sorted as the number one criterion, then the best alternative will have the smallest $R a$, or if the sorted $M R R$ is the number one criterion, the best alternative will have the largest $M R R$. In addition, the best-determined alternative depends on the ordering of the criteria and not on the weighting method.

From Table 16 it can be noted that:

- In columns (1), (2), (7) and (8), when MRR is selected as the number one indicator, $A_{16}$ is the best option. From Table 11 it can be seen that in this alternative, the $M R R$ also has the largest value $\left(M R R=6924 \mathrm{~mm}^{3} / \mathrm{min}\right)$.

- In columns (3), (4), (9) and (10), when $R z$ is selected as the first indicator, $A_{11}$ is considered the best option. In this option, $R z$ also has the small value among the total of 27 solutions. $R z$ in plan $A_{11}$ is equal to $4.01 \mu \mathrm{m}$, only a very small amount greater than $R z$ in plans $A_{7}, A_{10}, A_{22}$.

- When $F c$ is ranked as the number one criterion (column (5), (6), (11), (12)), $A_{11}$ is also determined to be the best option. In this alternative, $F c$ also has the smallest value among the total of 27 options, $F c=110(\mathrm{~N})$.

- The solution is determined to be the best depending only on the ordering of the criteria, not on the weighting method. This can also be due to the issue of mentioning the ideal alternative under the $M A R$ COS method. 


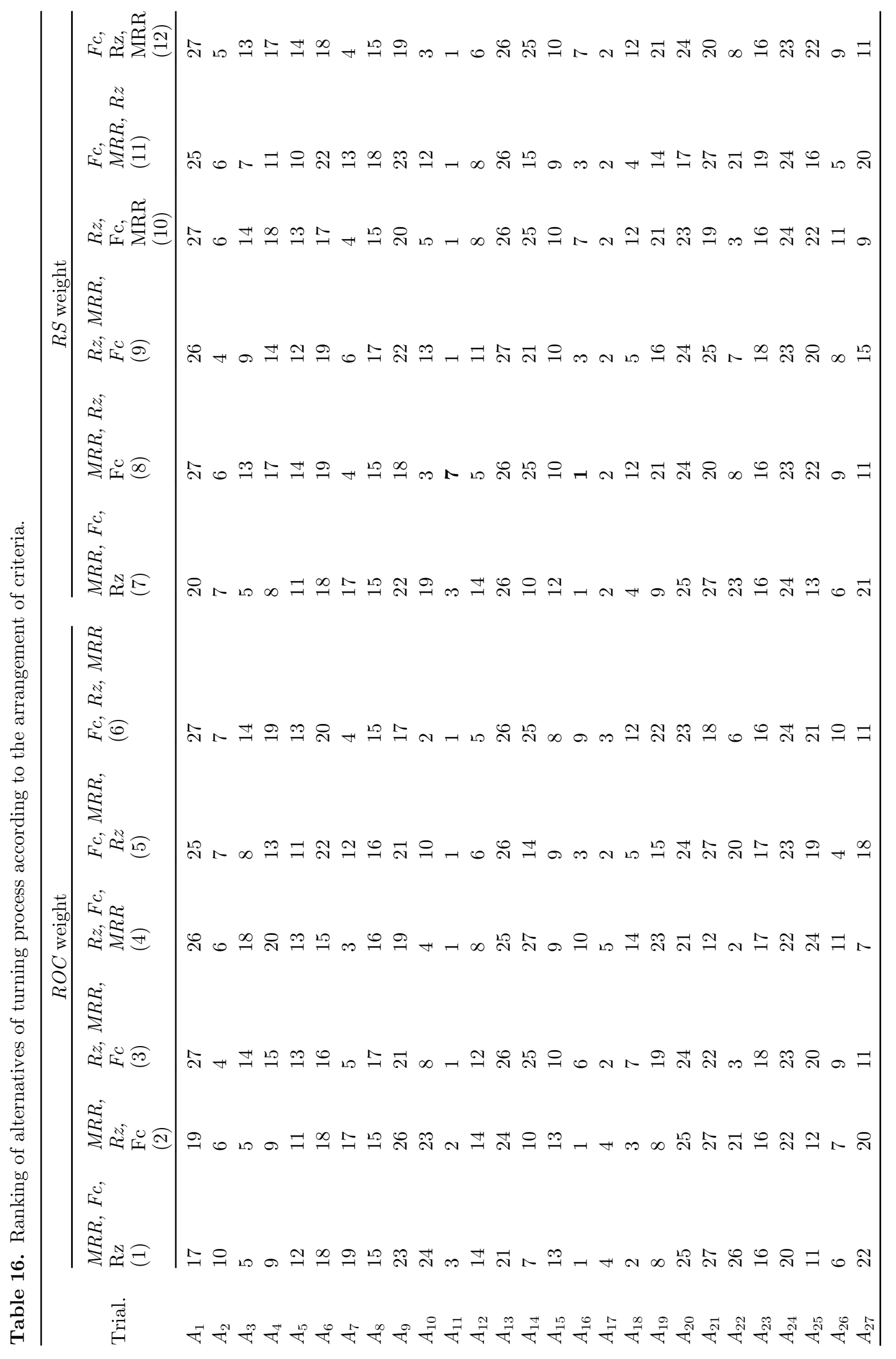




\section{Conclusions}

In this study, multi-criteria decision making for three different machining processes including milling, grinding and turning was performed. In each process, the weights of the indicators were determined according to four methods including the Equal weight method, the $R O C$ weight method, the $R S$ weight method, and Entropy weight method. The MARCOS alternative was first applied to multi-criteria decision making for mechanical processing. The effect of ordering the criteria on decision making to choose the best option has also been carefully considered, and some very interesting issues have been discovered. Some conclusions are drawn after applying all three machining methods as follows:

- When the weights of the criteria are determined by the Equal weight method and the Entropy weight method, the weighted values of the alternative do not depend on the ranking order of the criteria and the best solution is always indicated systematically between the two methods.

- When the weights of the alternatives are determined by methods where the value of the weights depends on the arrangement of the criteria (the $R O C$ weight, and the $R S$ weight criteria), the best solution is determined depending on the sort order of the criteria. When the same ordering of the criteria, the best solution is determined uniformly for both methods.

- When using two methods including the $R O C$ weight method and the $R S$ weight method, if the best alternative is to give priority to any criteria, that criteria need to be ranked at the first position in the order of ranking criteria.

- By referring to the ideal alternative, it appears that the MARCOS method always determines the best solution when the different weighting methods are used.

- Evaluation of the stability of the alternative rank using the different weighting methods as well as comparison of the MARCOS method with other multi-criteria decision making methods, such as TOPSIS, MOORA, VIKOR, etc. are necessary to be carried out in the future.

\section{Abbreviations}

MARCOS: Measurement Alternatives and Ranking according to COmpromise Solution

ROC: $\quad$ Rank Order Centroind

$R S: \quad$ Rank Sum

RIM: $\quad$ Reference Ideal Method

TOPSIS: Technique for Order of Preference by Similarity to Ideal Solution

PIV: $\quad$ Proximity Indexed Value

MOORA: Multi Objective Optimization on the basis of Ratio Analysis.

WASPAS: Weighted Aggregated Sum Product ASsessment

VIKOR: Vlsekriterijumska optimizacija I KOmpromisno Resenje
COPRAS: COmplex Proportional ASsessment.

PSI: $\quad$ Preference Selection Index

CURLI: Collaborative Unbiased Rank List integration

MRR: $\quad$ Material Removal Rate

Ra: $\quad$ The arithmetical mean deviation of the assessed profile

Rz: $\quad$ The minimum value of the profile maximum height

Fc: $\quad$ Cutting force

\section{References}

1. T.J. Ko, H.S. Kim, Surface integrity and machineability in intermittent hard turning, The International J. Adv. Manuf. Technol. 18 (2011) 168-175

2. D.D. Trung, N.V. Thien, N.T. Nguyen, Application of TOPSIS Method in Multi-Objective Optimization of the Grinding Process Using Segmented Grinding Wheel, Tribol. Ind. 43 (2021) 12-22

3. T.V. Dich, N.T. Binh, N.T. Dat, N.V. Tiep, T.X. Viet, Manufacturing technology, Science and Technics Publishing House, Ha Noi, (2003)

4. D.D. Trung, Multi-objective optimization of SKD11 steel milling process by reference ideal method, Int. J. Geol. 15 (2021) 1-16

5. V.C. Nguyen, T.D. Nguyen, D.H. Tien, Cutting Parameter Optimization in Finishing Milling of Ti-6Al-4V Titanium Alloy under MQL Condition using TOPSIS and ANOVA Analysis, Engineering, Technol. Appli. Sci. Res. 11 (2021) 6775-6780

6. N.L. Khanh, N.V. Cuong, The combination of taguchi and proximity indexed value methods for multi-criteria decision making when milling, Int. J. Mech. 15 (2021) 1-9

7. S.K. Shihab, A.K. Chanda, Multi response optimization of milling process parameters using moora method, Int. J. Mech. Prod. Eng. 3 (2015) 67-71

8. G.V.A. Kumar, D.V.V. Reddy, N. Nagaraju, Multi-objective optimization of end milling process parameters in machining of en 31 steel: application of ahp embedded with vikor and waspas methods, i-manager's, J. Mech. Eng. 8 (2018) 39-46

9. T. Ghosh, Y. Wang, K. Martinsen, K. Wang, A surrogateassisted optimization approach for multi-response end milling of aluminum alloy AA3105, Int. J. Adv. Manuf. Technol. 111 (2020) 2419-2439

10. N.T. Nguyen, D.D. Trung, combination of taguchi method, moora and copras technique in multi-objective optimization of surface grinding process, J. Applied Eng. Sci. 19 (2021) 390-398

11. D.H. Tien, D.D. Trung, N.V. Thien, N.T. Nguyen, Multiobjective optimization of the cylindrical grinding process of scm440 steel using preference selection index method, J. Mach. Eng. 21 (2021) 110-123

12. C. Maheswara Rao, K. Venkatasubbaiah, Application of mcdm approach-topsis for the multi-objective optimization problem, Int. J. Grid Distrib. Comput. 9 (2016) 17-32

13. N.V. Thien, D.H. Tien, D.D. Trung, N.T. Nguyen, Multiobjective optimization of turning process using a combination of taguchi and VIKOR methods, J. Applied Eng. Sci. (2021) 1-6 (Online first)

14. D.B. Prakash, G. Krishnaiah, Optimization of process parameters using AHP and vikor when turning AISI 1040 steel with coated tools, Int. J. Mech. Eng. Technol. 8 (2017) 241-248 
15. M. Abas, B. Salah, Q.S. Khalid, I. Hussain, A.R. Babar, R. Nawaz, R. Khan, W. Saleem, Experimental Investigation and Statistical Evaluation of Optimized Cutting Process Parameters and Cutting Conditions to Minimize Cutting Forces and Shape Deviations in Al6026-T9, Mater. 13 (2020) 1-21

16. A. Saha, H. Majumder, Multi criteria selection of optimal machining parameter in turning operation using comprehensive grey complex proportional assessment method for ASTM A36, Int. J. Eng. Res. Africa 23 (2016) 24-32

17. C.M. Rao, P.S. Reddy, D. Suresh, R.J. Kumar, Optimization of turning process parameters using psi-based desirabilitygrey analysis, Recent Adv. Mater. Sci. 2019 (2019) 231-246

18. R.K. Suresh, G. Krishnaiah, P. Venkataramaiah, Selection of best novel MCDM method during turning of hardened AISI D3 tool steel under minimum quantity lubrication using biodegradable oils as cutting fluids, Int. J. Applied Eng. Res. 12 (2017) 8082-8091

19. Z. Stevic, D. Pamucar, A. Puska, P. Chatterjee, Sustainable supplier selection in healthcare industries using a new MCDM method: Measurement Alternatives and Ranking according to COmpromise Solution (MARCOS), Comput. Ind. Eng. 140 (2020) 1-33

20. S. Tadic, M. Kilibarda, M. Kovac, S. Zecevic, The assessment of intermodal transport in countries of the Danube region, Int. J. Traffic Transp. Eng. 11 (2021) 375-391

21. S. Miomir, S. Zeljko, D.D. Kumar, S. Marko, P. Dragan, A New Fuzzy MARCOS Method for Road Traffic Risk Analysis, Mathematics 8 (2020) 1-17

22. A. Ulutas, D. Karabasevic, G. Popovic, D. Stanujkic, P.T. Nguyen, C. Karakoy, Development of a Novel Integrated CCSD-ITARA-MARCOS Decision-Making Approach for Stackers Selection in a Logistics System, Mathematics, 8 (2020) 1-15

23. Z. Stevic, N. Brkovic, A Novel Integrated FUCOMMARCOS Model for Evaluation of Human Resources in a Transport Company, Logistics 4 (2020) 1-15

24. H. Anysz, A. Nicał,Z. Stevic, M. Grzegorzewski,K. Sikora,Pareto optimaldecisionsinmulti-criteriadecisionmaking explained with construction cost cases, Symmetry 13 (2021) 1-25
25. K. Maniya, M.G. Bhatt, A selection of material using a novel type decision-making method: preference selection index method, Mater. Design 31 (2010) 1785-1789

26. J.R. Kiger, D.J. Annibale, A new method for group decision making and its application in medical trainee selection, Med. Educ. 50 (2016) 1045-1053

27. N. Gunantara, A review of multi-objective optimization: methods and its applications, Cogent Eng. 5 (2018) 1-21

28. D.D. Trung, A combination method for multi-criteria decision making problem in turning process, Manuf. Rev. 8 (2021) 1-17

29. E. Triantaphyllou, Multi-criteria Decision Making Methods, Springer, US (2000)

30. R.M. Dawes, B. Coorigan, Linear Models in Decision Malking, Psychol. Bull. 81 (1974) 95-106

31. H.J. Einhorn, W. Mccoach, A Symble multiattribute utility procedure for evaluation, Behav. Sci. 22 (1997) 270-282

32. D.D. Trung, N.T. Nguyen, D.V. Duc, Study on multiobjective optimization of the turning process of en 10503 steel by combination of taguchi method and moora technique, EUREKA: Phys. Eng. 2 (2021) 52-65

33. V.T.N. Uyen, N.H. Son, Improving accuracy of surface roughness model while turning $9 \mathrm{XC}$ steel using a Titanium Nitride-coated cutting tool with Johnson and Box-Cox transformation, AIMS Mater. Sci. 8 (2021) 1-17

34. D.V.K. Gupta, V.S. Sharma, V.S.M. Dogra, Wear mechanisms of tin-coated cbn tool during finish hard turning of hot tool die steel, proceedings of the institution of mechanical engineers, part B: J. Eng. Manuf. 224 (2010) $553-566$

35. S.R. Das, A. Panda, D. Dhupal, Experimental investigation of surface roughness, flank wear, chip morphology and cost estimation during machining of hardened AISI 4340 steel with coated carbide insert, Mech. Adv. Mater. Modern Processes 3 (2017) 1-14

36. V.R. Pathapalli, V.R. Basam, S.K. Gudimetta, M.R. Koppula, Optimization of machining parameters using WASPAS and MOORA, World J. Eng. 17 (2020) 237-246

Cite this article as: Do Duc Trung, Multi-criteria decision making under the MARCOS method and the weighting methods: applied to milling, grinding and turning processes, Manufacturing Rev. 9, 3 (2022) 